Original Research Article

\title{
A comparison of computer assisted learning and practical animal experiment for undergraduate medical students in pharmacology curriculum - a questionnaire based study conducted in a medical college of North India
}

\author{
Diwanshu Sharma*, Pavan Malhotra
}

Department of Pharmacology, ASCOMS, Jammu, Jammu and Kashmir, India

Received: 11 September 2016 Accepted: 12 October 2016

\section{*Correspondence to: \\ Dr. Diwanshu Sharma, Email: diwanshusharma2007 @ gmail.com}

Copyright: (C) the author(s), publisher and licensee Medip Academy. This is an openaccess article distributed under the terms of the Creative Commons Attribution NonCommercial License, which permits unrestricted noncommercial use, distribution, and reproduction in any medium, provided the original work is properly cited.

\begin{abstract}
Background: The practical sessions in pharmacology training involving animal experiments were perceived to be unnecessary as the learning objectives of these practical sessions primarily focus on observational, analytical and interpretative skills. A number of computer simulation and other models have been recommended for use as alternatives to use of animals for medical education. In this study, we compared Computer Assisted Learning (CAL) with practical animal experiments for medical undergraduates based on questionnaire. The objective of the study was to compare Computer Assisted Learning and practical animal experiments for medical undergraduates in pharmacology curriculum.
\end{abstract}

Methods: This was a questionnaire based observational study involving 300 medical undergraduates and eighteen faculty members. It included two systems i.e. CAL and conventional animal experiments. A separate questionnaire was prepared for the faculty members.

Results: Results showed that CAL has nearly replaced the practical laboratory experiments as far as the medical undergraduate training is concerned. All the students and teachers believed that CAL is better and more understandable than animal experiments done practically.

Conclusions: It is concluded that CAL is a better source of experimentation at the undergraduate level and provides dependable outcomes.

Keywords: Computer assisted learning, Medical undergraduates, Practical animal experiments

\section{INTRODUCTION}

There's no benefit in torturing an animal and also there's no good reason to inflict unnecessary pain on any living being. The big question arises here that when we can study a topic without using animals, should we do that or not? When we use animals in scientific study, we should be as kind to them as we possibly can .The use of animals in the field of research and education dates back to the time when humans started searching for the ways to prevent and cure ailments. Most of present day drug discoveries were possible because of the use of animals in research. The dilemma to use animal for experiments in education and research continues with varied and confusing guidelines. However, the animal use and their handling vary in each laboratory and educational institution. It has been reported that the animals are being subjected to painful procedures during experimentation unnecessarily. The extensive use of animals in toxicity studies and testing dermatological preparations has raised concerns about the ways animals are sacrificed for these "irrelevant exercises". On one side are the activists who promote the idea of cruelty to animals and on the other side are the scientists who advocate the relevant and judicious use of animals in research so that new discoveries can continue. However this is the most debated topic world over among the scientific community.

The practical sessions in pharmacology training involving animal experiments were perceived to be unnecessary by medical students, educationists and other policy makers as the learning objectives of these practical sessions primarily focus on observational, analytical and 
interpretative skills, which are components of the cognitive domain and not psychomotor domain. ${ }^{1,2} \mathrm{~A}$ number of computer simulation and other models have been recommended for use as alternatives to use of animals for medical education. In this study, we compare between Computer Assisted Learning (CAL) and practical animal experiments for medical undergraduates based on questionnaire.

\section{METHODS}

A questionnaire was prepared containing ten questions and 300 MBBS students of three different batches and 18 faculty members, were asked to answer the questionnaire. It included two systems i.e. CAL and conventional animal experiments. The questionnaire includes the following questions as shown in Table 1.

\section{RESULTS}

It was observed that $100 \%$ medical undergraduates favoured the use of computer simulation. All the medical undergraduates found $\mathrm{CAL}$ much easier compared to practical animal experiments. It was observed that CAL was considered better for self-assessment unlike practical animal experiments. Students found CAL quicker, time independent and were more confident about exercises with CAL as repetition with same exercise was possible. Another advantage of CAL is that, it is self-explanatory. Majority considered that CAL was better for examination purpose though $75 \%$ students considered practical animal experiments better as far as understanding was concerned. It was observed that even teachers believed that CAL was much better than practical animal experiments as far as undergraduate teaching is concerned. When the cost of conventional practical experiments was compared with that of the CAL it was calculated to be more than that of CAL. To install CAL cost spent was around 75000 rupees or in other words we can say that it was one time investment except monthly electricity bills whereas cost of conventional animal experiments was much more than that of CAL and was recurring kind of investment. Recurring investment done for traditional animal experiments included buying of animals, their diet, maintenance of animal house, electricity, employing veterinary doctor, animal keeper, cost of vaccination, cost of incineration and waste disposal.

When feedback was taken from faculty members they even believed CAL was better than practical animal experiments in nearly all perspectives unlike in certain aspects like practical animal experiments had a major role to play in drug development, to assess drug safety and to study the effect of substances in living body.

Results show that CAL has nearly replaced the practical laboratory experiments as far as the medical undergraduate training is concerned.100\% students and teachers believe that CAL is better and more understandable than animal experiments done practically.

Table 1: Questionnaire based comparison between Computer assisted learning (CAL) and practical animal experiments for medical undergraduates and analysis of feedback from undergraduates' medical students and Faculty members.

\begin{tabular}{|c|c|c|c|c|c|}
\hline \multirow[t]{2}{*}{ No } & \multirow[t]{2}{*}{ Questions } & \multicolumn{2}{|l|}{ CAL } & \multicolumn{2}{|c|}{ Practical animal experiments } \\
\hline & & $\begin{array}{l}\text { Faculty } \\
\text { members }(\%)\end{array}$ & $\begin{array}{l}\text { Medical UGs } \\
(\%)\end{array}$ & $\begin{array}{l}\text { Faculty } \\
\text { members }(\%)\end{array}$ & $\begin{array}{l}\text { Medical UGs } \\
(\%)\end{array}$ \\
\hline 1. & $\begin{array}{l}\text { Which do you think has a better } \\
\text { understanding? }\end{array}$ & 99 & 25 & 1 & 75 \\
\hline 2. & Which of the two is easy? & 100 & 100 & 0 & 0 \\
\hline 3. & $\begin{array}{l}\text { Between the two, which is time } \\
\text { consuming? }\end{array}$ & 0 & 0 & 100 & 100 \\
\hline 4. & $\begin{array}{l}\text { Which can help in a better way for } \\
\text { self-assessment through MCQs? }\end{array}$ & 100 & 100 & 0 & 0 \\
\hline 5. & Which is quicker? & 100 & 100 & 0 & 0 \\
\hline 6. & Where repetition is possible? & 100 & 100 & 0 & 0 \\
\hline 7. & $\begin{array}{l}\text { Which do you think is time } \\
\text { independent? }\end{array}$ & 100 & 100 & 0 & 0 \\
\hline 8. & $\begin{array}{l}\text { Which between the two is } \\
\text { interesting? }\end{array}$ & 100 & 26 & 0 & 74 \\
\hline 9. & Which is self-explanatory? & 100 & 100 & 0 & 0 \\
\hline 10. & $\begin{array}{l}\text { Which of the two would be better } \\
\text { for examination? }\end{array}$ & 94 & 94 & 6 & 6 \\
\hline
\end{tabular}




\section{DISCUSSION}

Here a questionnaire based comparison was done between CAL and practical animal experiments for medical undergraduates. It was observed that unlike traditional animal experiments CAL is much better in every aspect as far as the undergraduate teaching is concerned. Various advantages and disadvantages were observed during the course of study.

\section{Advantages of computer assisted learning}

CAL is helpful for both students and teachers. Modern computers with multimedia capabilities and presentational benefits can provide an interactive and personalized learning experience and thus promote active and self-directed learning. ${ }^{3,4}$ It offers an advantage to the students to learn at their convenience and pace; it can save the time as well as resources of the faculty. ${ }^{5}$

The best thing about CAL is that, it meets most of the learning objectives. There is supporting evidence from many medical schools that CAL is the best suitable alternative to practical laboratory classes and successfully meets the learning objectives of the sessions. ${ }^{2,5-9}$ These learning objectives include the cognitive domain (understanding the pharmacological effects) as well as skill components like communication skills. CAL increases the understanding of the theoretical concepts when it is applied in the setting of simulated experiments. ${ }^{10} \mathrm{CAL}$ also adds to enable students to have better understanding under familiar circumstances during self-study; it can extend the learning experience into fields which are too costly or time consuming and also staff expertise may not be available. ${ }^{11}$

The drug effects can be easily appreciated in simulations and cumbersome experimental exercises become easier to understand. Biological variations observed in the animal experiments may demoralise students and also waste time as well as resources unlike animal simulations that provide results that is reproducible. These experiments can be observed repeatedly without the loss of animals as well as experimental errors. ${ }^{1,4}$ The effects of drugs at varying dose ranges can be well seen on CAL, which otherwise would be time consuming when performed on animals. In case of CAL, large number of students can perform the experiment at the same time at their respective places and on their individual computers, whereas the animal experiments are usually conducted among groups of students and that also if animals are available in required quantity. There's appreciable reduction in cost when CAL is used unlike cost involved with use of animal experiments. Studies have documented that computer simulations of animal experiments are more cost effective than establishing and maintaining animal houses. Leathard HL et al. study reported the total cost of carrying out sessions on the GI motility with CAL was around $£ 320$ and $£ 860$ with tutor demonstration of animal experiments.
CAL concentrates on understanding of the subject rather than psychomotor skill acquisition. The assessment methods for CAL sessions are related to the assessment of the cognitive domain whereas the conventional methods are based more on animal handling skill and to lesser extent on knowledge. The good about these assessments is that the higher levels of cognitive domain like analysis can also be tested. Communication skills can also be assessed with the use of interactive multimedia softwares. $^{7}$

\section{Disadvantages of CAL}

For scientific change there are pros and cons, similar is the case with CAL. In a virtual laboratory environment, there are certain things like making up of drug solutions in varying dilutions and dosage, setting up and use of experimental equipment's, administration of test drugs and monitoring of the physiological signs cannot be properly taught, which pharmacology teachers consider essential in pharmacology training.

In CAL there no handling of living tissue and neither any observation of variations in responses in living tissue i.e. there is no practical knowledge. CAL may be easily forgotten in comparison to traditional animal experiments. ${ }^{1}$ Computer simulated exercises have prefixed doses therefore students cannot observe biological response at different doses. CAL is expensive in the initial stages of implementation in the curriculum. Technical problems with computer occurring during the class are other disadvantages with CAL. Technical snags are commonly encountered during CAL learning session which can be precluded with good technical support. ${ }^{9}$ Development of CAL software is labor intensive, requiring appropriate hardware, backup and frequent upgrading. Many teachers are not well versed in developing software and require help from technology staff.

\section{CONCLUSION}

It is concluded that CAL is a better source of experimentation at least at the undergraduate level for the various reasons discussed. Also an important issue is of ethics. Animal ethics is an issue as important as human welfare. So, for the welfare of one species other should not be sacrificed when it is not going to be helpful to the mankind since during routine teaching of pharmacology animal sacrifices can be conveniently avoided and effective implementation of 3 strategy Rs (Reduction, refinement and replacement) is required. For these alternative protocols to animal experimentation especially CAL provides dependable outcomes. Also the nonanimal methods are direct replacements since the use of animals receives more scrutiny and permission to conduct a clinical trial is easy rather than performing the animal experiments. 
Funding: No funding sources

Conflict of interest: None declared

Ethical approval: Not required

\section{REFERENCES}

1. Dewhurst D. Is it possible to meet the learning objectives of undergraduate pharmacology classes with non-animal models? AATEX. 2008;14:207-12.

2. Hughes IE. Do computer simulations of laboratory practicals meet learning needs? Trends Pharmacol Sci. 2001;22:71-4.

3. Moss S. Computer technology in education. Pharm J. 1993;251:491.

4. Baby LT, Kavalakkat JC, Abraham S, Sathianarayanan S. CAL: A modern tool for Pharmacology. Internet $\mathbf{J}$ of Medical Simulation. 2009;2:2.

5. Brain S, Dewhurst D, Williams A. Evaluation of a computer-based learning program to support student learning in pharmacology. ALT-J. 1999;7:37-45.

6. Dewhurst DG, Hardcastle J, Hardcastle PT, Stuart E. Comparison of a computer simulation program and a traditional laboratory practical class for teaching the principles of intestinal absorption. Am J Physiol. 1994;267:S95-104.

7. Leathard HL, Dewhurst DG. Comparison of cost effectiveness of a computer assisted learning program with tutored demonstration to teach intestinal motility to medical students. ALT-J. 1995;3:118-25.

8. Wang L. Computer-simulated pharmacology experiments for undergraduate pharmacy students: Experience from an Australian university. Indian $\mathbf{J}$ Pharmacol. 2001;33:280-2.

9. Govindaraja C, Jaiprakash H, Annamalai C, Vedhavathy SS. Computer assisted learning: Perceptions and knowledge skills of undergraduate medical students in a Malaysian medical school. Natl J Physiol Pharm Pharmacol. 2011;1:63-7.

10. Sewell RD, Stevens RG, Lewis DJ. Pharmacology experimental benefits from the use of computer assisted learning. Am J Pharm Educ. 1996;60:303-7.

11. Hughes IE. Computer-based learning-an aid to successful teaching of pharmacology? Naunyn Schmiedebergs Arch Pharmacol. 2002;366:77-82.

Cite this article as: Sharma D, Malhotra P. A comparison of computer assisted learning and practical animal experiment for undergraduate medical students in pharmacology curriculum - a questionnaire based study conducted in a medical college of North India. Int J Basic Clin Pharmacol 2016:5:2581-4. 